\title{
Fingerprint and Palmprint Recognition using Neighborhood Operation and FAST Features
}

\author{
Swapnali G. Garud", Apurva D. Dhawale ${ }^{2}$, Mazhar Kazi ${ }^{3}$, Y.S.Rode ${ }^{4}$, S.B.Dabhade ${ }^{5}$ K.V. \\ Kale ${ }^{6}$ \\ Department of Computer Science and IT, \\ Dr. Babasaheb Ambedkar Marathwada University, Aurangabad, (M.S.), India
}

\begin{abstract}
In this paper presents biometrics based fingerprint and palmprint recognition and authentication system. Fingerprint and palmprint images are enhanced using preprocessing techniques such as morphological operations. The feature extraction techniques such as neighborhood operation and FAST feature algorithm is used to independently extract fingerprint and palmprint features. These techniques are more reliable and faster than traditional techniques used. Experimental results shown recognition rate $89.29 \%$ for fingerprint and $100 \%$ for palmprint this implies that the proposed methodology has better performance and is more reliable over the techniques proposed and used earlier.
\end{abstract}

\author{
Abbrevations \\ SF - Single Flat \\ SFF - Single Flat Flexi \\ LT - Left Thumb finger \\ LI - Left Index finger \\ LM - Left Middle finger \\ LR - Left Ring finger \\ LL - Left Little finger \\ RT - Right Thumb \\ RI - Right Index finger \\ RM - Right Middle finger \\ RR - Right Ring finger \\ RL - Right Little finger \\ ROC- Receiver Operating Characteristics
}

\section{Keywords}

Multimodal, Neighborhood operation, FAST features, Region properties, Single Flat (SF), Single Flat Flexi, Euclidean.

\section{INTRODUCTION}

Nowadays biometric authentication system becomes very popular in various applications such as physical access control, security, monitoring. Password based security systems are widely used for protection from theft and crackers. But it is not proper practice each time to remember long passwords. In biometrics an individual is identified with the help of behavioral and physiological characteristics. It gives more security than passwords based security systems. Biometrics can be employed on various traits like fingerprint, palmprint, handgeometry, iris, face, voice, signature, etc.

\subsection{Biometrics overview}

Biometrics is of three modes i.e. unimodal biometrics which can identify individual by using single trait. Second is bimodal biometrics in which identification is done with fusion of two modalities and the other is multimodal biometrics which uses combination of multiple traits for identification purpose of human. A unimodal biometric may fails to be accurate enough for the identification of a large user population and there is one more possibility of failure if physical characteristics of a person for the selected biometric is not available [1].

Biometrics system has two types i.e. verification systems and identification systems.

- In a Verification System the input is a claimed identity and a biometric record. The system compares that biometric record with the biometric record stored in database for that identity to verify the claimed identity. In this system only a comparison is performed.

- In an Identification System the input is a biometric record. The system must search a database looking for the biometric data most similar with an input query biometric data and must decide if both of them belong to the same person. Many comparisons are required for this system [2].

\subsection{Biometrics Performance}

In real practice the chance of any two people having the same characteristic will be optimized by highly unique features [3]. By combining information from different biometrics modalities we can achieve higher and more consistent performance levels [4]. A multimodal biometric system requires an integration scheme to fuse information obtained from the individual modalities [5].

In multi-modal biometric system, there are generally four sorts of fusion level i.e.

1. Fusion at sensor level: - In this strategy images are fused directly or using some transform technique then features are extracted from fused image.

2. Fusion at feature-extraction level: - In this strategy the features extracted using two or more sensors are concatenated.

3. Fusion at matching-score level: - In this strategy matching scores obtained from multiple matchers are combined.

4. Fusion at decision level: - In this strategy the accept/reject decisions of multiple systems are consolidated.

The widely accepted strategy is feature extraction level because many observers prove that this level fusion produces better results. Usually, the performance of the biometric system is given by the accuracy of the system. There are two most widely used standard metrics of the accuracy of biometric systems i.e. 
False Accept Rate (FAR) and False Reject Rate (FRR). The FAR is the percentage of imposters that are incorrectly accepted by system. The FRR is the percentage of valid users who are incorrectly denied access by system.

In this paper new method is provided for personal authentication using fingerprint, palmprint that are simultaneously acquired from a single hand image. The database of subject for left and right hand is used in this system. Each of these palmprint images are used to extract specific features. Thus the palmprint and hand geometry features of an individual are obtained from the same hand image.

A fingerprint is composed of ridges and furrows which are parallel and have same width. A fingerprint image acquired by an Optical Sensor. The actual number of minutiae depends on the size of the sensor surface and how the user places his or her finger on the sensor [6]. They are distinguished by Minutiae which are features on the ridges. Two minutia types are more significant:-

1) Termination: - This is the immediate ending of a ridge.

2) Bifurcation: - This is the point on the ridge from which two branches derive.

The palm is the inner surface of a hand between the wrist and the fingers. There are different features that exists on a palm such as principle line, wrinkle line, delta point [7].

\section{RELATED WORK}

Gawande, U. et al [1] proposed a feature-level fusion framework for combining features of Iris and Fingerprint and algorithm Radial Basis Function based neural network (RBFNN) with accuracy rate $97.3 \%$. In paper[2] Teddy Ko gives various scenarios in multimodal biometric systems using fingerprint, face and iris recognition, the levels of fusion that are possible and the integration strategies that can be adopted to fuse information and improve overall system accuracy. How the image quality of traits will affect the overall identification accuracy and the need of staffing for the secondary human validation . V. C. Subbarayudu, et al [2] proposed general working of multimodal biometrics system with Iris and Palmprint and fusion is done at the matching score level by Sum Rule technique with recognition rate is $96.6 \%$. Andrew Teoh, et al [4] introduced k-Nearest Neighbourhood (k-NN) based classifiers are adopted in the decision fusion module for the face and speech experts with Recogntion rate is $80.33 \%$. Slobodan Ribaric, et al [5] gives a bimodal biometric verification system for physical access control based on the features of the palmprint and the face, palm matching is based on the adapted HYPER method. And for face the $\mathrm{K}-\mathrm{L}$ transform is used for matching. bimodal system can achieve an EER (equal error rate) of $3.08 \%$ for $\mathrm{T}=0.748$ and the minimum TER (total error rate) $=5.94 \%$ for $\mathrm{T}=0.8$. Anil K. Jain , et al [6] described an automated fingerprint recognition system and listed key challenges and research opportunities in the field. The recognition rate is $95 \%$. Fan Yang et al [7] fingerprint, palm-print and hand-geometry are combined for person identity verification. Wavelet transform to extract the features from fingerprint and palm-print is used and hand-geometry feature (such as width and length) is extracted after the pre-processing phase. Feature level fusion and match score fusion together for identity.The weight values are calculated based on total minimum error. i.e. For weight1- 0.75,weight2- 0.25 . X. Wu., et al [8] proposed a palm print recognition system by extracting features using Sobel operators and using Hidden Markov Models (HMM) as classifiers. Ajay Kumar, et al [9] attempts to improve the performance of palmprint-based verification system by integrating hand geometry features. These features are then examined for their individual and combined performances. The recognition rate is $98.3 \%$.

Harpreet Singh, et al [10] have given iterative fuzzy approach for obtaining fused images Entropy values are provided in result as for Fuzzy algorithm entropy is 5.30 and for neuro fuzzy algorithm 4.89. Chun Wai Lau, et al [11] presents a multi-biometric verification system that combines speaker verification, fingerprint verification with face identification and equal error rates (EER) are $4.3 \%, 5.1 \%$ and the range of $(5.1 \%$ to $11.5 \%$ ) for matched conditions in facial image capture respectively. K. Ito, et al [12] suggested Multi-scale wavelet decomposition of palmprint images and using mean of each wavelet sub-block has been suggested .

M. Wang, et al [13] proposed 2D PCA and 2D LDA over conventional PCA have been reported to be better for palmprint recognition. V. Conti, et al [14] have proposed multimodal biometric system using two different fingerprints. The matching module integrates fuzzy logic methods for matching score fusion. Both decision level fusion and matching score level fusion were performed. Antonia Azzini, et al [15] given idea about using a fuzzy control system to manage a multimodal authentication system, checking the identity of a user during the entire session. The first biometric acquisition takes matching score 0.725 and the second biometric acquisition takes score 0.4860 .

Kornelije Rabuzin, et al [16] had suggested active rules in fuzzy logic are used for effective decision making in person identification. The recognition rate is $97 \%$.

Gawande, et al [17] used log Gabor filter can be used to extract the feature vectors from both Iris and Fingerprint and then they are concatenated. The phase data from $1 \mathrm{D} \log$ Gabor filters is extracted and quantized to four levels to encode the unique pattern of Iris and Fingerprint into bitwise biometric template. Hamming distance (HD) is used to generate a final match score. Yong Jian Chin, et al [18] proposed a multimodal biometrics system in which 2D gabor filter is used to extract features. The recognition rate is $98 \%$. Asim Baig, et al [19] proposed a state of the art framework for multimodal biometric identification system which can be adapted for any type of biometrics to provide smaller memory footprint and faster implementation. The recognition rate is $90 \%$. Cheng $\mathrm{Lu}$, et al [20] suggested idea which utilizes two or more individual modalities, like face, ear, and fingerprint, to improve the recognition accuracy by new dimensionality reduction method called Dimension Reduce Projection (DRP). The recognition rate is $95.8 \%$. Nicolas Tsapatsoulis, et al [21] presented an identification and authentication system based on hand geometry which used POLYBIO hand database. The recognition rate is $95 \%$.

Anil K. Jain, et al [22] given an overview of biometrics, emerging biometric technologies and their limitations, and examines future challenges. Mohammad Imran, et al [23] proposed a new hybrid approach to verification aspect of a multibiometric system and comparative analysis with traditional approaches such as multialgorithmic and multimodal versions of the same. The average EER of hybrid approach from different levels of fusion is $3.87 \%$ which shows that hybrid approach yields lower average EER. Mohamed K. Shahin, et al [24] introduced a multimodal biometric system (MMBS) based on fusion of whole dorsal hand geometry and fingerprints that acquires right and left $(\mathrm{Rt} / \mathrm{Lt})$ near-infra-red (NIR) dorsal hand geometry (HG) shape and (Rt/Lt) index and ring fingerprints (FP). Accuracy rate is $99.71 \%$. S. Palanikumar, et al [25] presented approach for enhancing 
palmprint image. The enhancement is based on curvelet which preserves the fine features without noise. The result gives high PSNR (Peak Signal-to-Noise Ratio) value for the Curvelet method. i.e. 38.1047 .

Feifei CUI, et al [26] proposed multimodal biometrics recognition based on score level fusion of fingerprint and finger vein. Recogntion rate is $98.74 \%$. Romaissaa Mazouni, et al [27] proposed a comparative study of several advanced artificial intelligence techniques (e.g. Particle Swarm Optimization, Genetic Algorithm, Adaptive Neuro Fuzzy Systems, etc.) as to fuse matching scores in a multimodal biometric system is provided. The fusion was performed under three data conditions: clean, varied and degraded. Some normalization techniques are also performed prior fusion so to enhance verification performance. The population based techniques (PSO, GA) gave very good results. Nishant Singh, et al [28] presents an efficient multimodal biometric system based on 4 slap fingerprint images. The system utilizes 4 slap fingerprint scanner to simultaneously collect fingerprints of multiple fingers on a hand in one image. Decision threshold is 0.9869 and FAR is $5.08 \%$. Ashutosh Kumar, et al [29] suggested the new approach where the palmprint images are mapped to Eigen-space and a robust code signature is generated from different camera snapshots of the same palm to incorporate tonal and lighting variations. To enable real-time identification, the signature is represented by a low dimensional feature vector to reduce computational overheads. Overall accuracy rate is $98.7 \%$. P.U. Lahane, et al [30] given the comparison of data base template and the input data is done with the help of hamming-distance matching algorithm. If the templates are matched we can allow the person to access the system. Gabor filter is used for fingerprint. Accuracy is $99.5 \%$.

Krishneswari, et al [31] proposed to investigate the performance of multimodal biometrics using palm print and fingerprint. Features are extracted using Discrete Cosine Transform (DCT) and attributes selected using Information Gain (IG). Results shows an average improvement of $8.52 \%$. D. Y. Liliana, et al [32] studied about biometrics of palm for identification system using block-based line detection for palm print feature extraction process, and chain code solved the hand geometric feature extraction. We combined those two respective features and recognized it using Dynamic Time Warping (DTW) method which was able to measure the distance between two different features. The accuracy rate is $89 \%$. Gawande, et al [33] gives use of the log Gabor filter to extract the feature vectors from both Iris and Fingerprint and then they are concatenated. Finally the phase data from $1 \mathrm{D} \log$ Gabor filters is extracted and quantised to four levels to encode the unique pattern of Iris and Fingerprint into bitwise biometric template. Hamming distance (HD) is used to generate a final match score. Experimental results was verified on database of 50 users accounting to FAR $=0 \%$ and FRR $=4.3 \%$. M. Dale, et al [34] presented palm texture using transform features and hand geometry features are represented as distances between different boundary points. The final decision is made by fusion at decision level. And accuracy rate is $99.5 \%$. S. Rao, et al [35] suggests image fusion using fuzzy and neuro fuzzy logic approaches utilized to fuse images from different sensors, for enhancing visualization.

Alima, et al [36] investigates a novel algorithm based on fusion of both fingerprint and fingervein biometrics which uses Monogenic Local Binary Pattern (MonoLBP). This operator integrate the original LBP (Local Binary Pattern) with both other rotation invariant measures such as local phase and local surface type. Recognition rate is 93\%. Mohamad Abdolahi, et al [37] proposed two biometric traits such as iris and fingerprint which uses Decision level fusion and Fuzzy logic as technic for the effect of each biometric result combination. Recognition rate is $71 \%$. H. Tyagi, et al [38] gives first process which is based on Gabor filter and second is based on Gaussian filter and in the fingerprint image preprocessing steps and after getting result by first step then use feature extraction and feature matching steps simultaneously and separately for each process. After apply all steps the FAR (False Accept Rate) and FRR (False Reject Rate) for both process separately are calculated and compare results on the basis of FAR and FRR of Gabor filter based and FAR and FRR of Gaussian Filter based. Which process has the reduced FAR and FRR this is the best process than other. The accuracy rate is $95 \%$.

\section{PROPOSED METHOD}

The proposed method includes various steps such as image aquisition of user from sensor, preprocessing operation to enhance the quality of image and feature extraction process to identify the features of an image. Finally, matching is done on the basis of specific features with database image and decision is made for identification.

The figure 1 shows the block diagram of biometrics identification system.

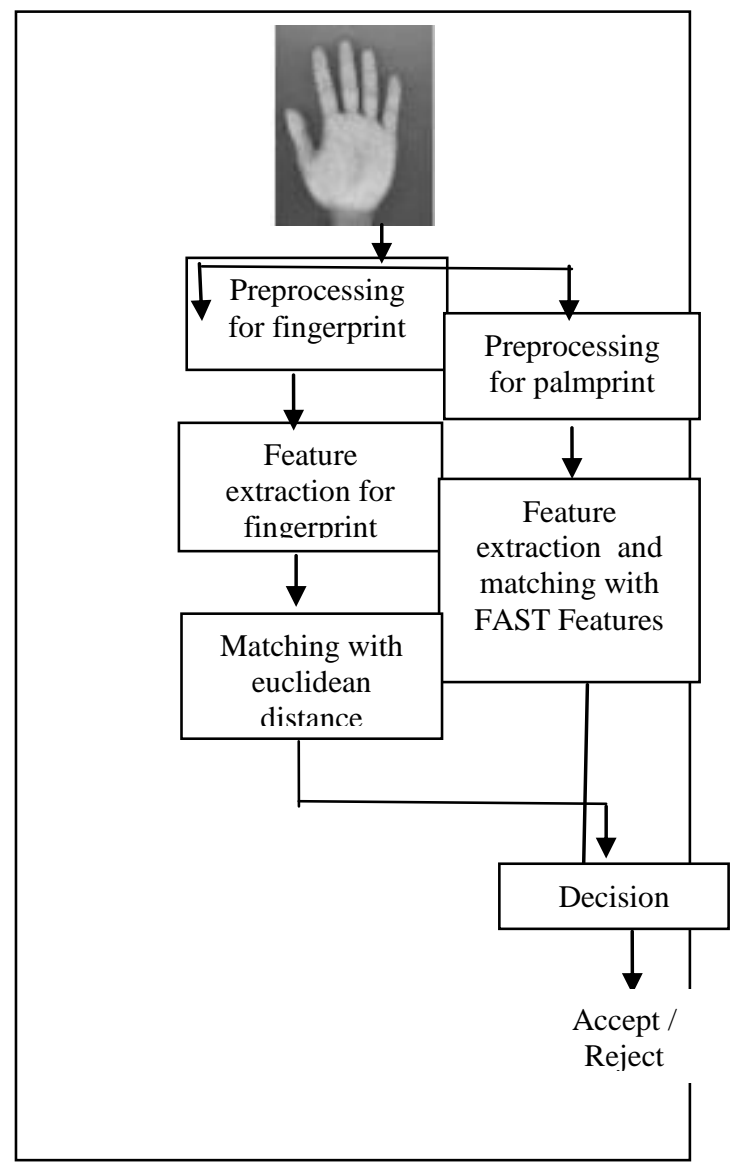

Fig 1 : Block Diagram Of Biometrics System 


\subsection{Image Acquisition}

\subsubsection{Extraction of fingerprint images}

For extraction of image we used the Crossmatch sensor. This sensor provides the facility of acquisition of fingerprint in various modes. Amongst these modes we selected the two modes in our research.

1) Single Flat Finger (SF):- In this mode specific area for image acquisition is provided by sensor. User supposed to be put finger on that area only. Accordingly all 10 fingers are scanned starting from left and continuing towards right.

2) Single flat flexi finger (SFF):- In this mode there is not any restriction about acquisition area of sensor. User can put finger on any place on acquisition area. This mode acquires the images for all 10 fingers for both hand starting from left little finger to right little finger.

We used KVKR Multimodal Biometrics database. It contains data of total 1120 images for fingerprint of 7 subjects. For single flat mode we used 8 samples of each subject and each individual sample contains images for all 10 fingers. So total number of images for SF is 560 ans SFF is 560. Similarly for single flat flexi mode we use same procedure.

\subsubsection{Extraction of Palmprint images}

For extraction of palmprint images whole handgeometry images are employed. Palmprint images are taken from the center of rectangle that can enclose the whole area of interest in palm. These center coordinates are used to extract a square palmprint region of fixed size. We used total 112 images of palmprint from database 8 images for left and right hand of subjects. Hence 16 images of every subject.

\subsection{Preprocessing techniques}

\subsubsection{Preprocessing for Fingerprint images}

Fingerprint images are grayscale images. They are converted into binary images. Then we perform morphological operation such as morphological thining. It removes pixels so that an object without holes shrinks to a minimally connected stroke, and an object with holes shrinks to a connected ring halfway between each hole and the outer boundary. After that we used median fliter then general sliding-neighborhood operations to extract minutiae as feature for fingerprint.

\subsubsection{Preprocessing of palmprint images}

For palmprint images we used center region of handgeometry images of specific size. These images are also colored images and we convert them firstly into grayscale images. Then specific threshold value is set for images for further processing.

\subsection{Feature extraction}

\subsubsection{Feature extraction for Fingerprint images}

For fingerprint we had extracted minutiae as feature because this features are more widely appears in every user. There are many variations in finger placement and pressure applied on the sensor, the minutia points extracted from the template and query fingerprints must be aligned, or registered before matching. We had extracted minutiae such as ridge bifurcations and endings. These features called as level 2 features which are useful to establish a fingerprint's individuality or uniqueness. If fingerprint image resolution is high then only higher-level features. We used general sliding-neighborhood operations with median filter and nlfilter 3-by-3 neighborhood. With the help of we extract minutiae as termination and bifurcation for all samples. After this we divide the total population into training and testing matrix. First 6 samples were considered as training samples and mean is taken for those samples for all fingers for each subject. And remaining 2 samples of termination and bifurcation of each subject is considered as testing sample. Feature matrix for fingerprint of termination where SF and SFF feature matrix are taken is individually for left and right hand. And after this SF and SFF termination were considered in combination as shown below in Table1 and Table2.

Table 1: Feature matrix for SF and SFF termination in combination for Left hand

\begin{tabular}{|c|c|c|c|c|c|c|c|c|c|c|}
\hline \multicolumn{7}{|c|}{ SF } \\
\hline & $\boldsymbol{L} \boldsymbol{T}$ & $\boldsymbol{L} \boldsymbol{I}$ & $\boldsymbol{L M}$ & $\boldsymbol{L R}$ & $\boldsymbol{L} \boldsymbol{L}$ & $\boldsymbol{L} \boldsymbol{T}$ & $\boldsymbol{I}$ & $\boldsymbol{L M}$ & $\boldsymbol{L R}$ & $\boldsymbol{L} \boldsymbol{L}$ \\
\hline Sub1 & 270 & 232 & 346 & 333 & 216 & 229 & 122 & 287 & 318 & 183 \\
\hline Sub2 & 480 & 202 & 210 & 387 & 248 & 338 & 172 & 140 & 256 & 284 \\
\hline Sub3 & 427 & 350 & 399 & 440 & 277 & 410 & 334 & 429 & 419 & 272 \\
\hline Sub4 & 853 & 468 & 953 & 868 & 596 & 699 & 395 & 804 & 742 & 556 \\
\hline Sub5 & 421 & 283 & 525 & 662 & 482 & 319 & 292 & 368 & 588 & 491 \\
\hline Sub6 & 309 & 282 & 325 & 429 & 161 & 392 & 425 & 546 & 750 & 472 \\
\hline Sub7 & 968 & 584 & 994 & 661 & 423 & 756 & 433 & 672 & 596 & 476 \\
\hline
\end{tabular}

Table 2 : Feature matrix for SF and SFF termination in combination for Right hand

\begin{tabular}{|l|l|l|l|l|l|l|l|l|l|l|}
\hline \multicolumn{9}{|c}{ SF } & \multicolumn{7}{c|}{ SFF } \\
\hline & $\boldsymbol{R} \boldsymbol{R}$ & $\boldsymbol{R} \boldsymbol{I}$ & $\boldsymbol{R} \boldsymbol{M}$ & $\boldsymbol{R} \boldsymbol{R}$ & $\boldsymbol{R} \boldsymbol{L}$ & $\boldsymbol{R} \boldsymbol{T}$ & $\boldsymbol{R I}$ & $\boldsymbol{R} \boldsymbol{M}$ & $\boldsymbol{R} \boldsymbol{R}$ & $\boldsymbol{R} \boldsymbol{L}$ \\
\hline Sub1 & 223 & 220 & 213 & 273 & 345 & 159 & 138 & 197 & 317 & 389 \\
\hline Sub2 & 455 & 240 & 145 & 241 & 222 & 297 & 229 & 157 & 182 & 181 \\
\hline Sub3 & 467 & 350 & 292 & 378 & 269 & 391 & 259 & 298 & 293 & 278 \\
\hline Sub4 & 771 & 612 & 742 & 645 & 479 & 612 & 549 & 751 & 796 & 641 \\
\hline Sub5 & 410 & 487 & 563 & 500 & 559 & 299 & 388 & 344 & 404 & 462 \\
\hline Sub6 & 419 & 365 & 517 & 480 & 297 & 443 & 628 & 679 & 712 & 459 \\
\hline Sub7 & 1064 & 707 & 871 & 695 & 530 & 1075 & 736 & 868 & 829 & 675 \\
\hline
\end{tabular}

Similarly, We had taken the feature matrix for bifurcation of left hand and right hand of each subject for Single Flat (SF) and Single Flat Flexi (SFF) individually. An after that SF and SFF in combination for each subject. Feature matrix for fingerprint of bifurcation where SF and SFF feature matrix are combine as shown below in Table 3 and Table 4.

Table 3 Feature Matrix For SF And SFF Bifurcation In Combination For Left Hand

\begin{tabular}{|l|c|c|c|c|c|c|c|c|c|c|}
\hline \multicolumn{9}{|c|}{ SF } & \multicolumn{5}{c|}{ SFF } \\
\hline & $\boldsymbol{L} \boldsymbol{T}$ & $\boldsymbol{L I}$ & $\boldsymbol{L M}$ & $\boldsymbol{L R}$ & $\boldsymbol{L} \boldsymbol{L}$ & $\boldsymbol{L T}$ & $\boldsymbol{L I}$ & $\boldsymbol{L M}$ & $\boldsymbol{L R}$ & $\boldsymbol{L} \boldsymbol{L}$ \\
\hline Sub1 & 260 & 236 & 367 & 372 & 239 & 219 & 110 & 296 & 341 & 186 \\
\hline Sub2 & 471 & 194 & 198 & 419 & 251 & 312 & 155 & 124 & 244 & 284 \\
\hline Sub3 & 454 & 374 & 439 & 492 & 292 & 427 & 354 & 480 & 473 & 302 \\
\hline Sub4 & 871 & 500 & 1199 & 990 & 705 & 718 & 437 & 414 & 823 & 649 \\
\hline Sub5 & 415 & 345 & 606 & 778 & 563 & 297 & 294 & 395 & 652 & 540 \\
\hline Sub6 & 320 & 302 & 368 & 525 & 189 & 401 & 444 & 618 & 944 & 574 \\
\hline Sub7 & 1103 & 585 & 755 & 725 & 480 & 794 & 424 & 682 & 669 & 481 \\
\hline
\end{tabular}


Table 4 Feature Matrix For SF And SFF Bifurcation In Combination For Right Hand

\begin{tabular}{|c|c|c|c|c|c|c|c|c|c|c|}
\hline \multicolumn{9}{|c}{ SF } & \multicolumn{6}{c|}{ SFF } \\
\hline & $\boldsymbol{R} \boldsymbol{T}$ & $\boldsymbol{R I}$ & $\boldsymbol{R M}$ & $\boldsymbol{R} \boldsymbol{R}$ & $\boldsymbol{R} \boldsymbol{L}$ & $\boldsymbol{R} \boldsymbol{T}$ & $\boldsymbol{R I}$ & $\boldsymbol{R M}$ & $\boldsymbol{R} \boldsymbol{R}$ & $\boldsymbol{R} \boldsymbol{L}$ \\
\hline Sub1 & 220 & 228 & 221 & 292 & 396 & 148 & 133 & 184 & 329 & 424 \\
\hline Sub2 & 456 & 244 & 136 & 233 & 224 & 286 & 222 & 144 & 166 & 175 \\
\hline Sub3 & 461 & 366 & 313 & 400 & 287 & 405 & 269 & 319 & 323 & 291 \\
\hline Sub4 & 847 & 714 & 892 & 764 & 550 & 809 & 596 & 885 & 964 & 756 \\
\hline Sub5 & 431 & 569 & 684 & 590 & 690 & 294 & 427 & 353 & 451 & 533 \\
\hline Sub6 & 434 & 402 & 58 & 580 & 345 & 446 & 720 & 781 & 886 & 554 \\
\hline Sub7 & 1195 & 787 & 1030 & 860 & 622 & 1218 & 771 & 962 & 967 & 782 \\
\hline
\end{tabular}

\subsubsection{Feature extraction for Palmprint images}

For palmprint we extracted features such as corners points in grayscale images with the Features from Accelerated Segment Test (FAST) algorithm to find feature points. Then from these corner points we extract interest point descriptors. These corner points are common for both images in the form of Index Pair. This algorithm also gives value of total number of Index pairs in images. Greater the value of index pair indicates that the images belongs to same subject and smaller value of index pair shows that the images belongs to different subject. The descriptors are extracted feature vectors and their corresponding locations, from a binary or intensity image. The function derives the descriptors from pixels surrounding an interest point. These pixels describe and match features specified by a single-point location. Each single- point specifies the center location of a neighborhood. The method used for descriptor extraction depends on the class of the input points such as SURFpoints, MSERobjects, corner points. FASTfeatures technique uses parameters as image, name and its scalar threshold value in the range $(0,1)$. Name is MinContrast i.e. Minimum intensity difference between corner and surrounding region, specified as the comma-separated pair consisting of MinContrast. The minimum intensity represents a fraction of the maximum value of the image class. Increasing the value reduces the number of detected corners. The default value is 0.2 . A standard threshold value used in this experiment is 0.031 beacuse at this particular threshold value we get maximum number of matching index pairs in images.

Table-5 : Feature Matrix Palmprint Palmprint Images For Left Hand

\begin{tabular}{|l|r|r|r|r|r|r|r|}
\hline Sub & $\begin{array}{l}\text { Index } \\
\text { Pair1 }\end{array}$ & $\begin{array}{l}\text { Index } \\
\text { Pair2 }\end{array}$ & $\begin{array}{l}\text { Index } \\
\text { Pair3 }\end{array}$ & $\begin{array}{l}\text { Index } \\
\text { Pair4 }\end{array}$ & $\begin{array}{l}\text { Index } \\
\text { Pair5 }\end{array}$ & $\begin{array}{l}\text { Index } \\
\text { Pair6 }\end{array}$ & $\begin{array}{l}\text { Index } \\
\text { Pair7 }\end{array}$ \\
\hline Sub1 & 31.6 & 33 & 31 & 29.4 & 24.14 & 29.6 & 27.4 \\
\hline Sub2 & 16.9 & 31 & 33.8 & 26.3 & 41.12 & 41.4 & 31.6 \\
\hline Sub3 & 18.6 & 17.37 & 65 & 69.6 & 7 & 18.8 & 17.8 \\
\hline sub4 & 15.5 & 15.12 & 5.12 & 5.5 & 11.25 & 10.8 & 56.5 \\
\hline sub6 & 2.62 & 4.87 & 3.25 & 3.25 & 3.62 & 3.25 & 4 \\
\hline Sub7 & 1.5 & 1.25 & 1.63 & 1.75 & 1.12 & 2 & 2.37 \\
\hline
\end{tabular}

Table 6 : Feature Matrix Palmprint Palmprint Images For Right Hand

\begin{tabular}{|l|r|r|r|r|r|r|r|}
\hline Sub & $\begin{array}{l}\text { Index } \\
\text { Pair1 }\end{array}$ & $\begin{array}{l}\text { Index } \\
\text { Pair2 }\end{array}$ & $\begin{array}{l}\text { Index } \\
\text { Pair3 }\end{array}$ & $\begin{array}{l}\text { Index } \\
\text { Pair4 }\end{array}$ & $\begin{array}{l}\text { Index } \\
\text { Pair5 }\end{array}$ & $\begin{array}{l}\text { Index } \\
\text { Pair6 }\end{array}$ & $\begin{array}{l}\text { Index } \\
\text { Pair7 }\end{array}$ \\
\hline Sub1 & 23.38 & 25.50 & 90.50 & 11.50 & 33.13 & 28.00 & 7.88 \\
\hline Sub2 & 16.88 & 31.00 & 33.75 & 26.25 & 41.13 & 41.38 & 31.63 \\
\hline Sub3 & 5.13 & 5.00 & 8.25 & 7.50 & 8.38 & 9.88 & 9.63 \\
\hline Sub4 & 23.63 & 21.25 & 14.25 & 15.75 & 12.75 & 15.25 & 24.25 \\
\hline Sub5 & 9.88 & 15.00 & 19.63 & 14.75 & 20.25 & 16.25 & 15.00 \\
\hline Sub6 & 10.88 & 12.75 & 14.63 & 12.63 & 15.75 & 13.88 & 14.50 \\
\hline Sub7 & 3.25 & 3.25 & 2.63 & 3.25 & 4.38 & 1.38 & 0.63 \\
\hline
\end{tabular}

\section{EXPERIMENT AND RESULT ANALYSIS}

\subsection{Fingerprint Recognition}

In Fingerprint we used termination and bifurcation as features. For this we used general sliding-neighborhood operations with nlfilter 3-by-3 neighborhood. With the help of this we can extract minutiae as feature for fingerprint. After this we calculated the pairwise Euclidean distance between training matrix and testing matrix for SF mode of Left hand and right hand for termination. In same manner we calculated the pairwise Euclidean distance for SFF mode Left hand and right hand for termination. For better performance we take the Euclidean distance for SF and SFF in combination for left and right hand termination. The resulting distance matrix is as shown in following table:-

Table 7: Distance Matrix for SF And SFF Termination In Combination For Left Hand

\begin{tabular}{|l|l|c|c|c|c|c|c|}
\hline & Sub1 & Sub2 & Sub3 & Sub4 & Sub5 & Sub6 & Sub7 \\
\hline $\begin{array}{l}\text { Sub } \\
\mathbf{1 - 7}\end{array}$ & 296.28 & 452.22 & 678.92 & 1725.58 & 907.01 & 882.78 & 1645.73 \\
\hline $\begin{array}{l}\text { Sub2- } \\
\mathbf{7}\end{array}$ & 469.77 & 184.61 & 472.81 & 1392.50 & 695.88 & 750.44 & 1294.54 \\
\hline $\begin{array}{l}\text { Sub3- } \\
\mathbf{7}\end{array}$ & 474.41 & 484.32 & 324.26 & 1242.91 & 500.63 & 433.14 & 1213.14 \\
\hline $\begin{array}{l}\text { Sub4- } \\
\mathbf{7}\end{array}$ & 1493.30 & 1533.37 & 1170.11 & 473.58 & 976.00 & 1071.91 & 703.06 \\
\hline $\begin{array}{l}\text { Sub5- } \\
\mathbf{7}\end{array}$ & 932.17 & 952.99 & 741.77 & 879.63 & 465.66 & 915.72 & 957.83 \\
\hline $\begin{array}{l}\text { Sub6- } \\
\mathbf{7}\end{array}$ & 1115.87 & 1146.61 & 771.09 & 564.47 & 569.34 & 733.26 & 663.77 \\
\hline $\begin{array}{l}\text { Sub7- } \\
\mathbf{7}\end{array}$ & 1335.42 & 1292.50 & 958.48 & 422.32 & 904.85 & 1072.35 & 341.68 \\
\hline $\begin{array}{l}\text { Sub1- } \\
\mathbf{8}\end{array}$ & 264.50 & 382.36 & 591.41 & 1611.61 & 866.76 & 865.47 & 1489.60 \\
\hline $\begin{array}{l}\text { Sub2- } \\
\mathbf{8}\end{array}$ & 569.40 & 362.89 & 534.08 & 1416.94 & 768.65 & 814.06 & 1318.31 \\
\hline $\begin{array}{l}\text { Sub3- } \\
\mathbf{8}\end{array}$ & 385.23 & 524.69 & 342.87 & 1213.05 & 398.47 & 577.77 & 1200.56 \\
\hline $\begin{array}{l}\text { Sub4- } \\
\mathbf{8}\end{array}$ & 1340.34 & 1337.85 & 989.68 & 613.43 & 905.50 & 863.77 & 754.09 \\
\hline $\begin{array}{l}\text { Sub5- } \\
\mathbf{8}\end{array}$ & 674.70 & 634.80 & 451.89 & 880.90 & 328.80 & 692.82 & 853.17 \\
\hline $\begin{array}{l}\text { Sub6- } \\
\mathbf{8}\end{array}$ & 1068.42 & 1143.77 & 830.68 & 1226.89 & 855.71 & 455.58 & 1275.80 \\
\hline $\begin{array}{l}\text { Sub7- } \\
\mathbf{8}\end{array}$ & 1255.47 & 1242.15 & 860.42 & 515.62 & 843.19 & 904.37 & 398.21 \\
\hline
\end{tabular}


In table 7 the highlighted cells indicates the correctly classified Sub5samples of each subject. And the highlighted values indicates 8 the misclassified values for each subject.

Table 8: Distance Matrix For SF And SFF Termination In Combination For Right Hand

\begin{tabular}{|c|c|c|c|c|c|c|c|}
\hline & Sub1 & Sub2 & Sub3 & Sub4 & Sub5 & Sub6 & Sub7 \\
\hline $\begin{array}{l}\text { Sub1- } \\
7\end{array}$ & 38.45 & 450.11 & 522.88 & 1458.52 & 773.10 & 1030.60 & 1979.31 \\
\hline${ }_{7}^{\text {Sub2- }}$ & 514.97 & 162.27 & 375.28 & 1409.26 & 837.30 & 1062.07 & 1830.45 \\
\hline $\begin{array}{l}\text { Sub3- } \\
7 \\
\end{array}$ & 2.68 & 407.67 & 212.93 & 1072.36 & 556.86 & 702.57 & 1524.83 \\
\hline $\begin{array}{l}\text { Sub4- } \\
7\end{array}$ & 1380.39 & 1341.61 & 1110.60 & 769.53 & 1044.44 & 31.63 & 855.72 \\
\hline $\begin{array}{l}\text { Sub5- } \\
7\end{array}$ & 16.39 & 832.73 & 56.33 & 730.12 & 169.05 & 563.67 & 1259.20 \\
\hline $\begin{array}{l}\text { Sub6- } \\
7\end{array}$ & 1191.54 & 1239.41 & 949.81 & 391.54 & 786.03 & 388.57 & 900.31 \\
\hline $\begin{array}{l}\text { Sub7- } \\
7\end{array}$ & 1903.16 & 1866.66 & 1572.03 & 619.06 & 1334.06 & 1137.22 & 185.57 \\
\hline $\begin{array}{l}\text { Sub1- } \\
8\end{array}$ & 261.75 & 413.10 & 365.28 & 1242.43 & 551.17 & 891.40 & 1763.50 \\
\hline $\begin{array}{l}\text { Sub2- } \\
8 \\
\end{array}$ & 46.58 & 123.78 & 330.21 & 1382.68 & 758.00 & 1035.09 & 1835.13 \\
\hline $\begin{array}{l}\text { Sub3- } \\
8\end{array}$ & 538.68 & 514.88 & 293.07 & 1092.38 & 492.84 & 761.16 & 1553.20 \\
\hline $\begin{array}{l}\text { Sub4- } \\
8 \\
\end{array}$ & 1494.54 & 1519.44 & 1249.83 & 616.56 & 1055.92 & 781.86 & 735.45 \\
\hline Sub5-8 & 655.94 & 800.23 & 566.27 & 923.57 & 243.14 & 754.16 & 1454.58 \\
\hline $\begin{array}{l}\text { Sub6- } \\
8 \\
\end{array}$ & 836.79 & 864.61 & 614.81 & 759.01 & 617.33 & 324.19 & 1258.37 \\
\hline $\begin{array}{l}\text { Sub7- } \\
8\end{array}$ & 1741.73 & 1703.60 & 1426.94 & 522.90 & 1200.99 & 1031.92 & 445.08 \\
\hline
\end{tabular}

After we take the euclidean distance for bifurcation of SF and SFF left and right hand individually and then in combination for left and right hand. The distance matrix of SF and SFF in combination for bifurcation is as shown in following table:-

\section{Table 9 : Distance Matrix For SF And SFF Bifurcation} In Combination For Left Hand

\begin{tabular}{|l|c|c|c|c|c|c|c|}
\cline { 2 - 8 } \multicolumn{1}{c|}{} & Sub1 & Sub2 & Sub3 & Sub4 & Sub5 & Sub6 & Sub7 \\
\hline $\begin{array}{l}\text { Sub1- } \\
\mathbf{7}\end{array}$ & 327.37 & 447.39 & 780.41 & 1885.33 & 1066.77 & 1107.93 & 1684.61 \\
\hline $\begin{array}{l}\text { Sub2- } \\
\mathbf{7}\end{array}$ & 487.61 & 181.80 & 576.23 & 1573.54 & 879.71 & 988.84 & 1284.16 \\
\hline $\begin{array}{l}\text { Sub3- } \\
\mathbf{7}\end{array}$ & 593.12 & 621.20 & 404.29 & 1366.62 & 589.80 & 530.29 & 1183.67 \\
\hline $\begin{array}{l}\text { Sub4- } \\
\mathbf{7}\end{array}$ & 1798.01 & 1900.30 & 1416.86 & 997.20 & 1193.38 & 1229.40 & 1010.50 \\
\hline $\begin{array}{l}\text { Sub5- } \\
\mathbf{7}\end{array}$ & 1204.77 & 1203.43 & 967.63 & 797.02 & 631.30 & 1222.45 & 922.24 \\
\hline $\begin{array}{l}\text { Sub6- } \\
\mathbf{7}\end{array}$ & 1550.31 & 1633.80 & 1160.34 & 730.43 & 837.45 & 981.38 & 915.26 \\
\hline $\begin{array}{l}\text { Sub7- } \\
\mathbf{7}\end{array}$ & 1478.56 & 1459.60 & 1049.32 & 674.43 & 976.80 & 1226.85 & 299.97 \\
\hline $\begin{array}{l}\text { Sub1- } \\
\mathbf{8}\end{array}$ & 297.16 & 382.55 & 690.74 & 1775.03 & 1022.85 & 1091.72 & 1535.80 \\
\hline $\begin{array}{l}\text { Sub2- } \\
\mathbf{8}\end{array}$ & 608.20 & 398.22 & 657.36 & 1610.95 & 971.70 & 1065.57 & 1335.34 \\
\hline $\begin{array}{l}\text { Sub3- } \\
\mathbf{8}\end{array}$ & 509.27 & 649.48 & 466.53 & 1281.90 & 421.77 & 764.32 & 1216.39 \\
\hline $\begin{array}{l}\text { Sub4- } \\
\mathbf{8}\end{array}$ & 1588.86 & 1636.66 & 1166.68 & 1050.20 & 1085.09 & 971.40 & 763.88 \\
\hline
\end{tabular}

Table 10: Distance Matrix For SF And SFF Bifurcation In Combination For Right Hand

\begin{tabular}{|l|c|c|c|c|c|c|c|}
\hline & Sub1 & Sub2 & Sub3 & Sub4 & Sub5 & Sub6 & Sub7 \\
\hline $\begin{array}{l}\text { Sub1- } \\
\mathbf{7}\end{array}$ & 178.55 & 504.50 & 582.19 & 1837.71 & 983.50 & 1216.46 & 2340.76 \\
\hline $\begin{array}{l}\text { Sub2- } \\
\mathbf{7}\end{array}$ & 543.33 & 152.41 & 450.93 & 1813.64 & 1070.59 & 1264.92 & 2231.93 \\
\hline $\begin{array}{l}\text { Sub3- } \\
\mathbf{7}\end{array}$ & 552.14 & 463.27 & 207.08 & 1402.25 & 753.60 & 890.53 & 1852.13 \\
\hline $\begin{array}{l}\text { Sub4- } \\
\mathbf{7}\end{array}$ & 1662.94 & 1654.81 & 1357.80 & 884.74 & 1293.60 & 1126.69 & 989.78 \\
\hline $\begin{array}{l}\text { Sub5- } \\
\mathbf{7}\end{array}$ & 921.87 & 1085.91 & 760.31 & 1027.96 & 201.50 & 1039.76 & 1519.71 \\
\hline $\begin{array}{l}\text { Sub6- } \\
\mathbf{7}\end{array}$ & 1477.08 & 1579.17 & 1215.52 & 593.41 & 1020.22 & 692.60 & 1094.31 \\
\hline $\begin{array}{l}\text { Sub7- } \\
\mathbf{7}\end{array}$ & 2350.36 & 2362.33 & 1998.57 & 735.44 & 1644.79 & 1743.78 & 303.11 \\
\hline $\begin{array}{l}\text { Sub1- } \\
\mathbf{8}\end{array}$ & 330.02 & 532.85 & 454.50 & 1601.87 & 710.08 & 1137.16 & 2087.78 \\
\hline $\begin{array}{l}\text { Sub2- } \\
\mathbf{8}\end{array}$ & 489.32 & 136.38 & 413.30 & 1787.33 & 993.57 & 1264.51 & 2221.24 \\
\hline $\begin{array}{l}\text { Sub3- } \\
\mathbf{8}\end{array}$ & 672.16 & 702.07 & 416.75 & 1369.54 & 608.19 & 1041.00 & 1810.75 \\
\hline $\begin{array}{l}\text { Sub4- } \\
\mathbf{8}\end{array}$ & 1781.69 & 1854.23 & 1515.50 & 738.85 & 1285.00 & 1114.80 & 960.88 \\
\hline $\begin{array}{l}\text { Sub5- } \\
\mathbf{8}\end{array}$ & 848.14 & 1039.08 & 751.74 & 1203.03 & 339.37 & 1082.42 & 1683.88 \\
\hline $\begin{array}{l}\text { Sub6- } \\
\mathbf{8}\end{array}$ & 1053.28 & 1128.74 & 805.11 & 975.85 & 820.84 & 602.08 & 1480.38 \\
\hline $\begin{array}{l}\text { Sub7- } \\
\mathbf{8}\end{array}$ & 2055.24 & 2073.44 & 1731.93 & 629.85 & 1402.87 & 1405.04 & 603.33 \\
\hline
\end{tabular}

The table 11 gives the analysis of results for SF and SFF termination when the samples tested individually.

\section{Table-11 : Recognition Rate For SF And SFF Termination When Tested Individually}

\begin{tabular}{|c|c|c|c|c|}
\hline Test & $\begin{array}{c}\text { Total } \\
\text { no of } \\
\text { sample }\end{array}$ & $\begin{array}{c}\text { Correct } \\
\text { classified }\end{array}$ & $\begin{array}{c}\text { Miss } \\
\text { classified }\end{array}$ & RR \\
\hline $\begin{array}{c}\text { SF Left } \\
\text { hand } \\
\text { Termination }\end{array}$ & 14 & 10 & 4 & $71.42 \%$ \\
\hline $\begin{array}{c}\text { SF Right } \\
\text { hand } \\
\text { Termination }\end{array}$ & 14 & 10 & 4 & $71.42 \%$ \\
\hline $\begin{array}{c}\text { SFF Left } \\
\text { hand } \\
\text { Termination }\end{array}$ & 14 & 13 & 1 & $92.85 \%$ \\
\hline $\begin{array}{c}\text { SFF Right } \\
\text { hand } \\
\text { Termination }\end{array}$ & 14 & 10 & 4 & $71.42 \%$ \\
\hline
\end{tabular}

It is observed that SFF mode gives better recognition rate for left hand than SF for termination.

Similarly, we analysed the results for bifurcation of SF and SFF when tested individually. Table 11 shows that recognition rate for SFF is better than SF for bifurcation also. 
Table-12 : Recognition rate for SF and SFF bifurcation when tested individually

\begin{tabular}{|c|c|c|c|c|}
\hline Test & $\begin{array}{c}\text { Total } \\
\text { no of } \\
\text { sample }\end{array}$ & $\begin{array}{c}\text { Correct } \\
\text { classified }\end{array}$ & $\begin{array}{c}\text { Miss } \\
\text { classified }\end{array}$ & RR \\
\hline $\begin{array}{c}\text { SF Left } \\
\text { hand } \\
\text { bifurcation }\end{array}$ & 14 & 7 & 7 & $50 \%$ \\
\hline $\begin{array}{c}\text { SF Right } \\
\text { hand } \\
\text { bifurcation }\end{array}$ & 14 & 9 & 5 & $64.28 \%$ \\
\hline $\begin{array}{c}\text { SFF Left } \\
\text { hand } \\
\text { bifurcation }\end{array}$ & 14 & 11 & 3 & $78.57 \%$ \\
\hline $\begin{array}{c}\text { SFF Right } \\
\text { hand } \\
\text { bifurcation }\end{array}$ & 14 & 11 & 3 & $78.57 \%$ \\
\hline
\end{tabular}

When we test the samples of SF and SFF in combination for termination and bifurcation then it is observed that the recognition rate is increased to $100 \%$ as compare to when test is done for individual for each mode.

Table 13 : Recognition Rate For SF And SFF Termination When Tested In Combination

\begin{tabular}{|c|c|c|c|c|}
\hline Test & $\begin{array}{c}\text { Total } \\
\text { no of } \\
\text { sample } \\
\text { tested }\end{array}$ & $\begin{array}{c}\text { Correct } \\
\text { classified }\end{array}$ & $\begin{array}{c}\text { Miss } \\
\text { classified }\end{array}$ & RR \\
\hline $\begin{array}{c}\text { SF and } \\
\text { SFF Left } \\
\text { hand } \\
\text { termination }\end{array}$ & 14 & 13 & 1 & $92.75 \%$ \\
\hline $\begin{array}{c}\text { SF and } \\
\text { SFF Right } \\
\text { hand } \\
\text { termination }\end{array}$ & 14 & 14 & 0 & $100 \%$ \\
\hline
\end{tabular}

Table 14 : Recognition Rate For SF And SFF Bifurcation When Tested In Combination

\begin{tabular}{|c|c|c|c|c|}
\hline Test & $\begin{array}{c}\text { Total } \\
\text { no of } \\
\text { sample } \\
\text { tested }\end{array}$ & $\begin{array}{c}\text { Correct } \\
\text { classified }\end{array}$ & $\begin{array}{c}\text { Miss } \\
\text { classified }\end{array}$ & RR \\
\hline $\begin{array}{c}\text { SF and } \\
\text { SFF Left } \\
\text { hand } \\
\text { bifurcation }\end{array}$ & 14 & 11 & 3 & $78.57 \%$ \\
\hline $\begin{array}{c}\text { SF and } \\
\text { SFF Right } \\
\text { hand } \\
\text { bifurcation }\end{array}$ & 14 & 12 & 2 & $85.71 \%$ \\
\hline
\end{tabular}

Total 56 test samples are tested for fingerprint. Out of which 50 are correctly classified and 6 are misclassified. The reason for miss-classification is the poor quality of images.

\subsection{Palmprint Recogntion}

In palmprint we used 112 images for 7 subject of both left and right hand. From 112 we used 98 for training and remaining 14 for testing matrix. We test at least two images at a time for palm. By comparing results of these two images we can easily recognize the particular subject. If the image sample belongs to same person then the both image contains maximum no of matching corner points in common called as index pair. If the images doesn't belongs to same person then they have no matching points in common or negligible matching points in common. We can compare the test image against no of images at the same time with this process. The resultant matrix contains total no of index pairs for each pair of tested image samples. This test gives appropriate idea about the test sample belongs to which subject. Afterwards this matrix for further analysis and ease of use is reduced to the classification matrix which contains the total no of samples correctly classified in particular class for each subject. And ' $x$ ' entry indicates that no match in corresponding class. The table 14 shows classification matrix for palmprint samples.

Table 15 : Classification Matrix For Palmprint Samples

\begin{tabular}{|c|c|c|c|c|c|c|c|}
\hline $\begin{array}{l}\text { Test } \\
\text { Sample }\end{array}$ & Sub1 & Sub2 & Sub3 & Sub4 & Sub5 & Sub6 & Sub7 \\
\hline & $\begin{array}{c}\text { Class- } \\
1\end{array}$ & $\begin{array}{c}\text { Class- } \\
2\end{array}$ & $\begin{array}{c}\text { Class- } \\
3\end{array}$ & $\begin{array}{c}\text { Class- } \\
4\end{array}$ & $\begin{array}{c}\text { Class- } \\
5\end{array}$ & $\begin{array}{c}\text { Class- } \\
6\end{array}$ & $\begin{array}{c}\text { Class- } \\
7\end{array}$ \\
\hline Sub1-8 & 8 & $\mathrm{x}$ & $X$ & $\mathrm{x}$ & $\mathrm{x}$ & $\mathrm{x}$ & $\mathrm{x}$ \\
\hline Sub2-8 & $\mathrm{x}$ & 8 & $X$ & $\mathrm{x}$ & $\mathrm{X}$ & $\mathrm{X}$ & $x$ \\
\hline Sub3-8 & $\mathrm{x}$ & $\mathrm{x}$ & 8 & $\mathrm{x}$ & $\mathrm{x}$ & $\mathrm{X}$ & $\mathrm{X}$ \\
\hline Sub4-8 & $\mathrm{x}$ & $\mathrm{x}$ & X & 8 & $\mathrm{x}$ & $\mathrm{x}$ & $\mathrm{x}$ \\
\hline Sub5-8 & $\mathrm{x}$ & $\mathrm{X}$ & $X$ & $\mathrm{x}$ & 8 & $\mathrm{X}$ & $\mathrm{X}$ \\
\hline Sub6-8 & $\mathrm{x}$ & $\mathrm{X}$ & X & $\mathrm{x}$ & $\mathrm{x}$ & 8 & $\mathrm{x}$ \\
\hline Sub7-8 & $\mathrm{x}$ & $\mathrm{x}$ & $X$ & $\mathrm{x}$ & $\mathrm{x}$ & $\mathrm{x}$ & 8 \\
\hline
\end{tabular}

Table 16 : Recognition Rate For Palmprint Samples

\begin{tabular}{|c|c|c|c|c|}
\hline Sub & $\begin{array}{c}\text { Total no } \\
\text { of sample tested }\end{array}$ & $\begin{array}{c}\text { Correct } \\
\text { classified }\end{array}$ & Miss Classified & RR \\
\hline Sub1 & 8 & 8 & 0 & \\
\hline Sub2 & 8 & 8 & 0 & \multirow{2}{*}{$100 \%$} \\
\cline { 1 - 4 } Sub3 & 8 & 8 & 0 & \\
\hline Sub4 & 8 & 8 & 0 & \\
\hline Sub5 & 8 & 8 & 0 & \\
\hline Sub6 & 8 & 8 & 0 \\
\hline Sub7 & 8 & 8 & \multicolumn{2}{|c|}{0} \\
\hline
\end{tabular}

From table 15 it is observed that all samples of palmprint are classified into corresponding classes correctly. So the recognition rate achieved for palmprint images is $100 \%$.

Table 17 : Overall Recognition Rate For Fingerprint And Palm

\begin{tabular}{|c|c|c|c|c|}
\hline Test & $\begin{array}{c}\text { Total } \\
\text { no of } \\
\text { sample } \\
\text { tested }\end{array}$ & $\begin{array}{c}\text { Correct } \\
\text { classified }\end{array}$ & $\begin{array}{c}\text { Miss } \\
\text { classified }\end{array}$ & RR \\
\hline Fingerprint & 56 & 50 & 6 & $89.29 \%$ \\
\hline Palm & 56 & 56 & 0 & $100 \%$ \\
\hline
\end{tabular}


Figure 2 shows the Receiver Operating Characteristic curve for fingerprint images and Figure 3 ROC curve for palmprint images. The ROC is based on observed frequency and cumulative frequency. Performance True positive rate and false positive rates are analyzed with the ROC.
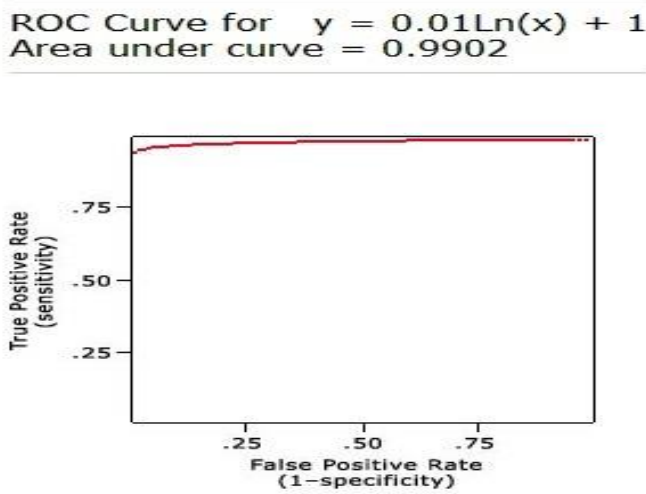

Fig 2 : ROC curve for fingerprint

$$
\text { ROC Curve for } y=0.01 \ln (x)+1
$$$$
\text { Area under curve }=0.9902
$$

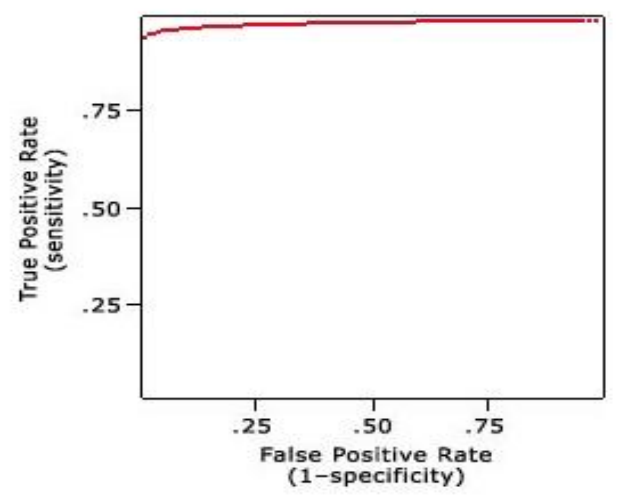

Fig 3 ROC curve for palmprint

\section{CONCLUSION}

The results clearly indicates the significance of the method used in this research work. The results of fingerprint recognition was improved because of combination of features of SF, SFF and achieved $89.29 \%$ recognition. Similarly for palm print recognition the FAST features were utilized for classification for palm into appropriate classes. The observed classification success is $100 \%$. These two methods can be collectively used for development of multimodal biometric recognition system in very effective way.

This paper presents a novel idea about person identification based on fingerprint and palmprint images. This work is more reliable because it gives faster results as compare to traditional biometric techniques. Fingerprint recognition consist of two modes of image acquisition. i.e. Single flat (SF) and Single flat flexi (SFF). Amongst which we get better recognition rate for Single flat flexi mode than Single flat mode. And the recognition rate is also increased upto $100 \%$ when tests are done in combination for Single flat and Single flat flexi as compare to test done individually.

For palmprint recogntion the new approach FAST feature algorithm reduces number of comparisons ad provides easy recognition rate because it gives direct discrimination between image samples.

\section{ACKNOWLEDGEMENT}

We would like to acknowledge and thanks to University Grants Commission (UGC), India for providing facility of UGC SAP (II) DRS Phase - I F. No. 3-42/2009 Biometrics: Multimodal System Development Laboratory.

\section{REFERENCES}

[1] Gawande U., Zaveri M. and Kapur A 2013 Fingerprint And Iris Fusion Based Recognition Using RBF Neural Network. Journal of Signal and Image Processing ISSN: 0976-8882 \& E-ISSN: 0976-8890, 4 (1).

[2] Teddy Ko 2005 Multimodal Biometric Identification for Large User Population Using Fingerprint, Face and Iris Recognition. IEEE transaction Proceedings of the 34th Applied Imagery and Pattern Recognition Workshop.

[3] V C Subbarayudu, Munaga V, N K Prasad, 2008 Multimodal biometrics system. Proceeding IEEE transactions.

[4] Andrew Teoh, S. A. Samad and A. Hussain, 2004 Nearest Neighbourhood Classifiers in a Bimodal Biometric Verification System Fusion Decision Scheme. Journal of Research and Practice in Information Technology, 36 (1).

[5] Slobodan Ribaric, Ivan Fratric, Kristina K. 2007 A Biometric Verification System Based on the Fusion of Palmprint and Face Features. Department of Electrical Engineering and Computing, University of Zagreb, Croatia.

[6] Anil K. Jain, Jianjiang Feng, Karthik Nandakumar, 2010 Biometrics : Fingerpeint Matching. Published by the IEEE Computer Society 0018-9162 .

[7] Fan Yang, Baofeng Ma. 2007 A New Mixed-Mode Biometrics Information Fusion Based-on Fingerprint, Hand-geometry and Palm-print. IEEE transactions Fourth International Conference on Image and Graphics.

[8] X. Wu, K. Wang, Zhang D. 2004 HMMs based palmprint identification LNCS 3072, pp. 775-781.

[9] Ajay Kumar, David C. M. Wong, Helen C. Shen, Anil K. Jain. 2004 Personal verification using Palmprint and Hand Geometry Biometric. Department of Computer Science, Hong Kong University of Science and Technology, Clear Water Bay, Hong Kong.

[10] Harpreet Singh, Jyoti Raj Gulsheen Kaur , Thomas Meitzler 2004 Image Fusion using Fuzzy Logic and Applications. Proceeding IEEE transactions .

[11] Chun Wai Lau, Bin Ma, Helen M. Meng, Y.S. Moon and Yeung Yam 2005 Fuzzy Logic Decision Fusion in a Multimodal Biometric System The Chinese University of Hong Kong, Hong Kong SAR, China.

[12] K. Ito, T. Aoki, H. Nakajima, K. Kobayashi, T. Higuchi 2006 A palmprint recognition algorithm using phase based image matching. Proceedings of the ICIP, pp. 2669-2672. 
[13] M. Wang, Q. Ruan. 2006 Palmprint recognition based on two dimensional methods. Proceedings of ICSP.

[14] V. Conti, G. Milici, P. Ribino, F. Sorbello and S. Vitabile 2007 Fuzzy Fusion in Multimodal Biometric Systems. university of 90127 Palermo, Italy.

[15] Antonia Azzini, Ernesto Damiani, Stefania Marrara, 2007 Ensuring the identity of a user in time: a multi-modal fuzzy approach. IEEE International Conference on Computational Intelligence for Measurement Systems and Applications Ostuni, Italy,

[16] Kornelije Rabuzin, Miroslav Ba., Markus Schatten, 2008 Fuzzy Active Rules in Mutimodal Biometric Systems. Proceedings of the ITI 2008 30th Int. Conf. on Information Technology Interfaces.

[17] Gawande U., Sreejith R Nair, Harsha Balani, Nikhil Pawar \& Manjiri Kotpalliwar 2009 High Speed Frequency Multimodal Biometric System Using Iris and fingerprint. Proceeding Springer.

[18] Yong Jian Chin, Thian Song Ong, Michael K.O. Goh and Bee Yan Hiew 2009 Integrating Palmprint and Fingerprint for Identity Verification. IEEE Third International Conference on Network and System Security.

[19] Asim Baig, Ahmed Bouridane, Fatih Kurugollu, GangQu. 2009 Fingerprint - Iris Fusion based Identification System using a Single Hamming Distance Matcher. Symposium on Bio-inspired Learning and Intelligent Systems for Security.

[20] Cheng Lu, Di Liu*, Jisong Wang, Shuyan Wang 2009 Multimodal Biometrics Recognition by Dimensionality Reduction Method. Second International Symposium on Electronic Commerce and Security.

[21] Nicolas Tsapatsoulis and Constantinos Pattichis 2009 Palm geometry biometrics : A score-based fusion Approach. Proceedings workshop AIAI.

[22] Anil K. Jain, Ajay Kumar 2010 Biometrics of Next Generation: An Overview. proceedings SECOND GENERATION BIOMETRICS' SPRINGER.

[23] Mohammad Imran , Ashok Rao , Hemantha Kumar G 2011 A New Hybrid approach for Information Fusion in Multibiometric Systems. Proceedings IEEE transactions.

[24] Mohamed K. Shahin, Ahmed M. Badawi, and Mohamed E. M. Rasmy 2011 Multimodal Biometric System Based on Near-Infra-Red Dorsal Hand Geometry and Fingerprints for Single and Whole Hands. World Academy of Science, Engineering and Technology 56.

[25] S. Palanikumar, M. Sasikumar and J. Rajesh 2011 Palmprint Enhancement Using Discrete Curvelet Transform. International Journal of Computer Science Issues, 8(4), No 2.

[26] Feifei CUI, Gongping Yang 2011 Level Fusion of Fingerprint and Finger Vein Recognition. Journal of Computational Information Systems, 7(16) pp. 5723-5731.
[27] Romaissaa Mazouni, Abdellatif Rahmoun 2011 On Comparing Verification Performances of Multimodal Biometrics Fusion Techniques. International Journal of Computer Applications (0975 - 8887), 33(7).

[28] Nishant Singh, Kamlesh Tiwari, Aditya Nigam and Phalguni Gupta 2012 Fusion of 4-Slap Fingerprint Images with Their Qualities for Human Recognition. IEEE transactions IEEE .

[29] Ashutosh Kumar, Ranjan Parekh 2012 Palmprint Recognition in Eigen-space. International Journal on Computer Science and Engineering (IJCSE) ISSN : 09753397, 4(1).

[30] P.U. Lahane, Prof. S.R. Ganorkar 2012 Efficient Iris and Fingerprint Fusion for Person identification. International Journal of Computer Applications (0975 8887), 50(17)

[31] Krishneswari, K. and S. Arumugam 2012 Multimodal Biometrics using Feature Fusion. Journal of Computer Science, 8 (3), 431-435.

[32] D. Y. Liliana, Eries Tri Utaminingsih 2012 The combination of palm print and hand geometry for biometrics palm recognition. International Journal of Video \& Image Processing and Network Security IJVIPNS-IJENS, 12(1).

[33] Gawande U. , Sreejith R Nair, Harsha Balani, Nikhil Pawar \& Manjiri Kotpalliwar 2012 A High Speed Frequency Multimodal Biometric System Using Iris and fingerprint. International Journal on Advanced Computer Engineering and Communication Technology (IJACECT) ISSN : 2278-5140, 1(2).

[34] M. P. Dale, M. A. Joshi, H. J. Galiyawala 2012 A Single Sensor Hand Geometry and Palm Texture Fusion for Person Identification. International Journal of Computer Applications (0975 - 8887), 42(7).

[35] Srinivasa Rao D, Seetha M, Krishna Prasad MHM Comparison Of Fuzzy And Neuro Fuzzy Image Fusion Techniques And Its Applications. International Journal of Computer Applications (0975 - 8887), 43(20).

[36] Alima Damak Masmoudi, Randa Boukhris Trabelsi and Dorra Sellami Masmoudi 2013 A new biometric human identification based on fusion fingerprints and fingerveins using MonoLBP descriptor. World Academy of Science, Engineering and Technology 78.

[37] Mohamad Abdolahi, Majid Mohamadi, Mehdi Jafari, 2013 Multimodal Biometric system Fusion Using Fingerprint and Iris with Fuzzy Logic. International Journal of Soft Computing and Engineering (IJSCE) ISSN: 2231-2307, 2(6)

[38] Hariom Tyagi, Dr. S.K. Singh 2013 Comparative Analysis of Gabor Filter Based and Gaussian Filter Based Fingerprint Recognition System. (IJRREST) ISSN 2278- 6643, 2(1). 